\title{
Partial Anomalous Left Pulmonary Artery: A Case Report and
}

\section{Literature Review}

\author{
Chia Hung Chen ${ }^{1}{ }^{1}$, Pei San Tsai ${ }^{1}$, Dao Chen Lin ${ }^{2}$, Yu Peng Liu $^{3}$ and Kun Shan Cheng ${ }^{4,}$ \\ ${ }^{1}$ Department of Radiology, Mackay Memorial Hospital, Taipei Branch, Mackay Junior College of Medicine, Nursing, and Management Taipei, Taiwan \\ ${ }^{2}$ Department of Radiology, Division of Endocrinology and Metabolism, Taipei Veterans General Hospital, School of Medicine, National Yang-Ming University, Taipei, Taiwan \\ ${ }^{3}$ Department of Radiology, Mackay Memorial Hospital, Hsinchu, Taiwan \\ ${ }^{4}$ Department of Pediatrics, Mackay Memorial Hospital, Hsinchu, Taiwan \\ "Corresponding author: Department of Pediatrics, Mackay Memorial Hospital, Hsinchu, Taiwan. Email: purifying@ym.edu.tw
}

Received 2020 January 01; Revised 2020 June 10; Accepted 2020 June 16.

\begin{abstract}
Hereby, the case of an 8-month-old girl diagnosed with partial anomalous left pulmonary artery (PLPA) is presented. Echocardiography and computed tomography (CT) examination demonstrated that the anomalous artery originated from the right pulmonary artery supplying the left upper lobe. PLPA is sometimes associated with tracheobronchial anomaly and congenital cardiovascular defects. A relationship between PLPA and Kabuki syndrome has also been suggested. Echocardiography and CT angiography can be used as accurate tools for identifying an anomalous left pulmonary artery and adjacent abnormal anatomic structures.
\end{abstract}

Keywords: Partial Anomalous Left Pulmonary Artery, Pulmonary Arterial Sling, CT Angiography

\section{Introduction}

Partial anomalous left pulmonary artery (PLPA) is an extremely rare type of aberrant pulmonary artery (1-3) and can be associated with tracheobronchial anomaly and congenital cardiac defect (2-5). In contrast to the typical aberrant pulmonary artery, which always leads to a pulmonary sling, PLPA usually does not cause airway compression. Most cases of PLPA involve the anomalous left lower artery $(3,6,7)$. We report the case of an 8-month-old infant with PLPA who developed focal stenosis of the left main bronchus with absence of symptoms. This is the first report of a case of an anomalous left upper artery supporting the hypothesis of pulmonary artery connection error (4).

\section{Case Presentation}

The patient was an 8-month-old girl with facial anomaly, low-set ears, and funnel chest accompanied by heart murmur. The cardiac murmur was classified as grade I/VI systolic murmur over the upper sternal border. Echocardiography revealed an abnormal branch formed in the middle segment of the right pulmonary artery (RPA) directed to the left side (Figure 1). Lack of prenatal examination record and fetal echocardiography prevented identification of congenital disorders. Cardiac computed tomography (CT) angiogram showed that the RPA gave off a branch arising from the posterior area that coursed left and upward, anterior to the left main bronchus (Figure $2 \mathrm{~A}$ ), supplying the left upper lung (Figure 2B). This was associated with a compression on the left main bronchus, resulting in focal segmental stenosis (Figure 3 ) and determined to be a PLPA. The main left pulmonary artery (LPA) originating from the main pulmonary artery supplied the left lower lobe. The RPA and aorta were located at the usual sites and displayed normal anatomy. The patient was followed up regularly in the outpatient department. Because there were no evident symptoms, surgical intervention was not considered. The patient's pediatrician suggested genomic testing for Kabuki syndrome because of the patient's facial anomaly and PLPA, but the parents refused.

\section{Discussion}

In general, the pulmonary artery originates from the sixth aortic arch in the embryogenic phase. The right arch turns into the right pulmonary artery (RPA), whereas the proximal segment of the left arch turns into the left pulmonary artery (LPA), and the distal segment develops into ductus arteriosus or ligamentum arteriosus. With regard to the cause of anomalous LPA, Jue et al. (1) hypothesized that the proximal left arch somehow fails to develop or 


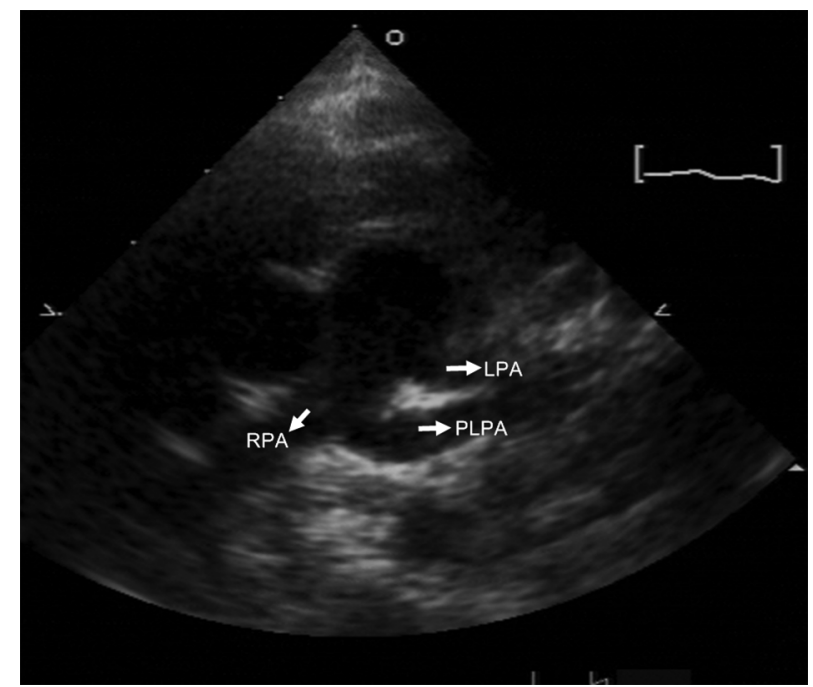

Figure 1. Echocardiogram showing partial anomalous left pulmonary artery (LPA) (PLPA) arising from the right pulmonary artery (RPA).
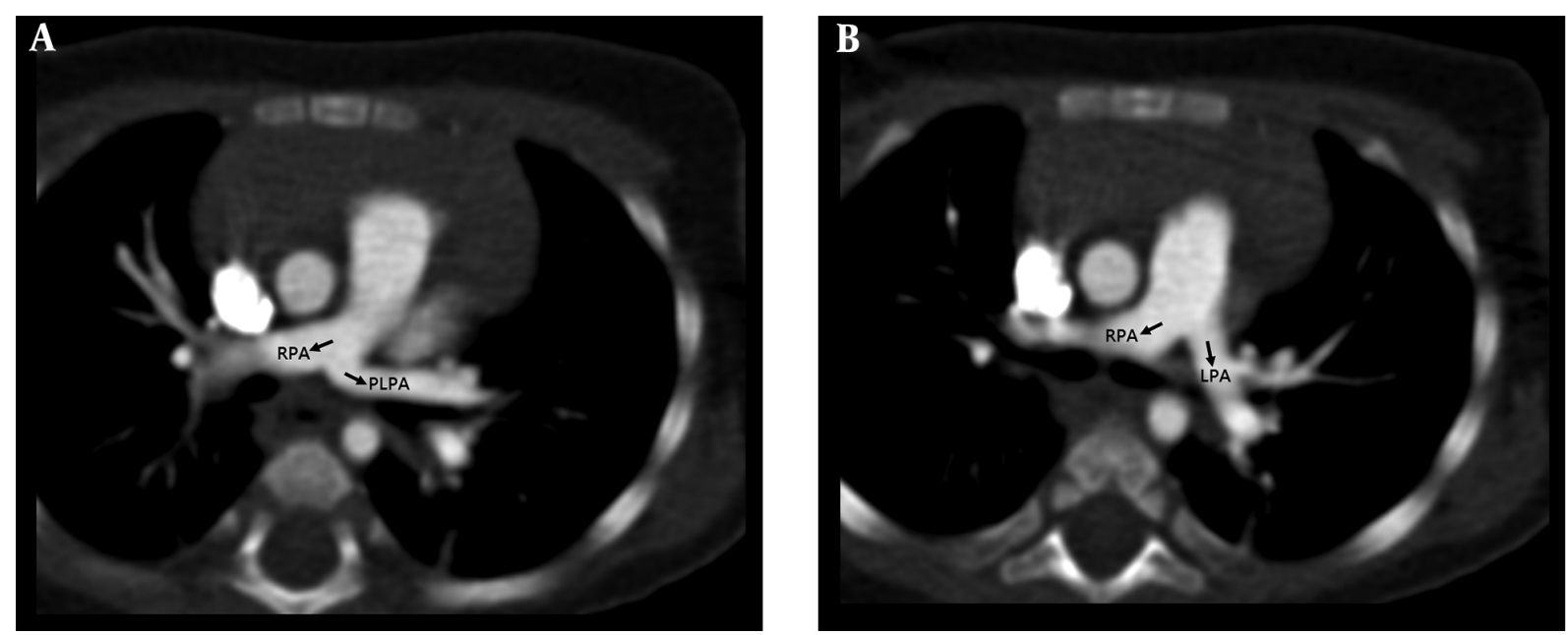

Figure 2. A, Partial anomalous left pulmonary artery (PLPA) arising from the main right pulmonary artery (RPA). B, The native left pulmonary artery (LPA) arises at the level of the carina. The branches of the PLPA serve the left upper lobe arteries.

is obliterated at an early stage, resulting in the supply to the left lung tissues being delivered by a collateral branch from the right arch. The collateral branch turns into the anomalous LPA if it remains. Another hypothesis (2) suggests that the anomalous LPA is actually the true LPA, but it develops into an aberrant connection and remains in close proximity to the ductus arteriosus. However, the abovementioned theories cannot explain the existence of PLPA. Bamman et al. (3) purported that PLPA could be due to a connection error of the pulmonary artery. Distal pulmonary arteries originate from the vascular plexus around the lung bud, and a developmental error may occur such that the left primitive pulmonary artery communicates with the twigs from the plexuses of the left and right lung buds, instead of the plexus of the left lung bud in the normal manner. If this communication persists, an anomalous vessel can result that originates from the RPA and supplies the left lung. In previous studies, all cases of PLPA were reported to originate from the left lower lobe artery. The current study is the first to report a case of a left upper lobe artery, and the study conducted by Bamman et al. provides a hypothesis with a satisfactory explanation for our finding (3).

PLPA is sometimes accompanied by tracheobronchial 

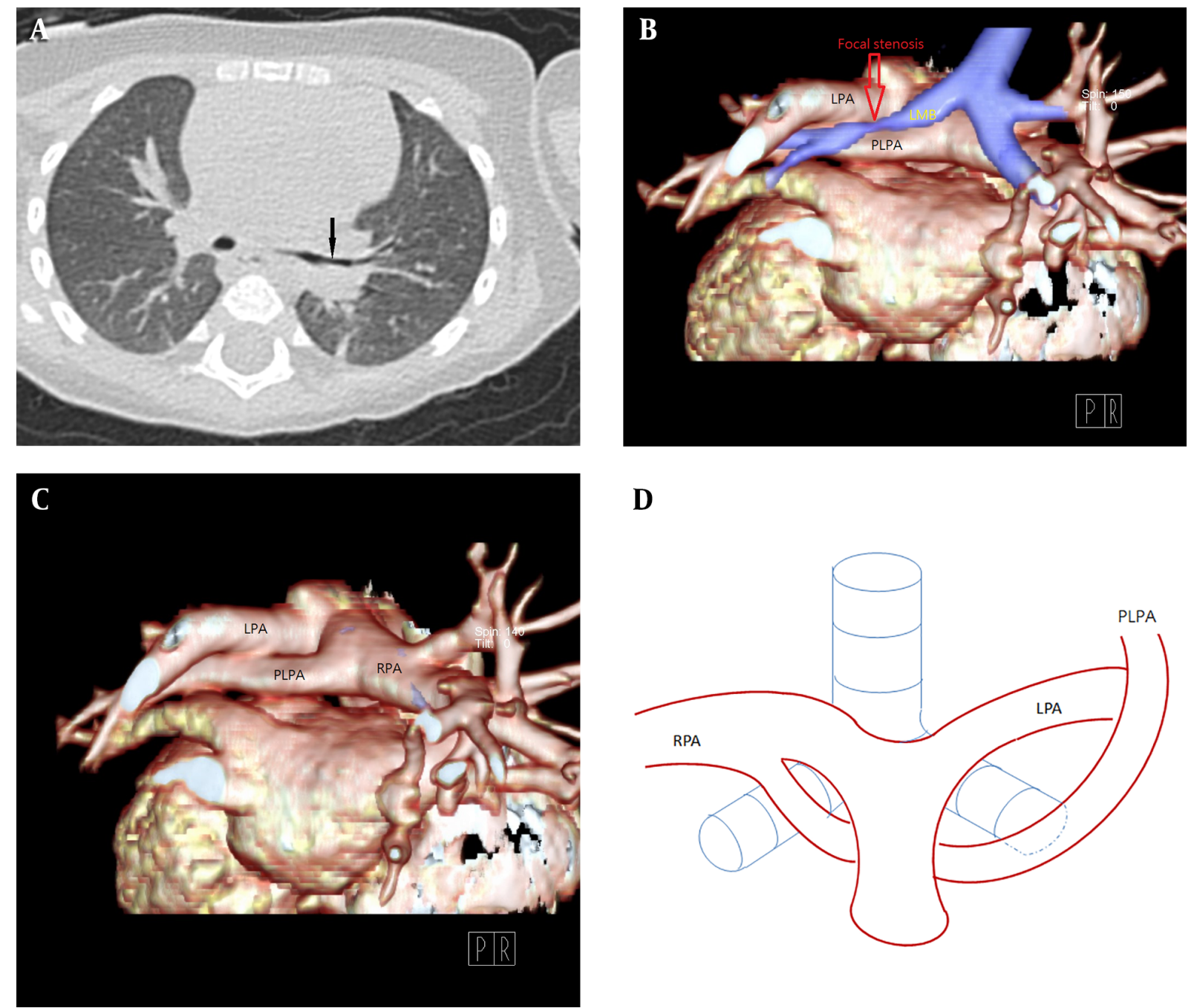

D

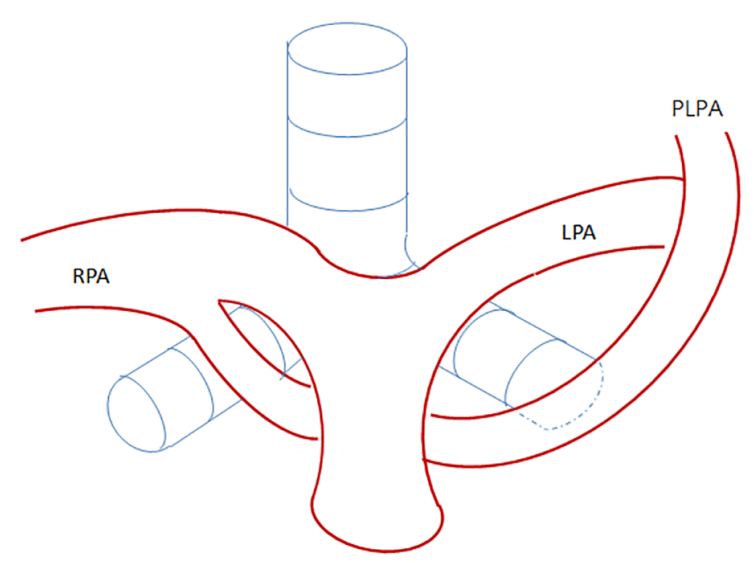

Figure 3. A, Chest CT in the lung window setting. B-C, 3D volume-rendered images showing focal stenosis of the left main bronchus (arrow) posterior to the partial anomalous left pulmonary artery (PLPA). D, The PLPA courses upward to supply the left upper lobe, labeled PLPA in the corresponding diagram in our case.

anomaly. There have been two reported circumstances including tracheal bronchus $(3,4)$ and bridging bronchus or horseshoe lungs (4-6). Unlike a typical pulmonary sling, PLPA only rarely causes tracheobronchial stenosis. Although the course is between the esophagus and trachea, the level is usually below the carina and does not lead to vascular compression. In addition to congenital tracheobronchial hypoplasia, Collins et al. (7) reported a case of diffusely smaller left lung bronchi and a lower perfusion state in the left hemi-lung, as noted on magnetic resonance imaging. This finding may suggest that the state of hypoperfusion results in hypoplasia of the affected bronchial tree.

Another associated abnormality of PLPA is congeni- tal cardiovascular defect, which could include ventricular septal defect, atrial septal defect, aortic coarctation, tetralogy of Fallot, total anomalous pulmonary venous return, and hypoplastic left heart syndrome. Such associations are suggestive of Kabuki syndrome, as reported previously by some studies (6-8). Kabuki syndrome consists of characteristic facial features, skeletal abnormalities, dermatoglyphic anomalies, and developmental and mental retardation. Most importantly, multiple congenital cardiac defects are also typically noted in reports of PLPA. To date, at least 30 cases of PLPA have been reported in the English research literature (Table 1) (3-15). Among them, Kabuki syndrome was confirmed or suspected in six patients, including the patient in the current case. 


\begin{tabular}{|c|c|c|c|c|c|c|}
\hline Authors (Reference) & Age & $\begin{array}{l}\text { Respiratory } \\
\text { symptoms }\end{array}$ & $\begin{array}{l}\text { Tracheobronchial } \\
\text { tree anomaly }\end{array}$ & Cardiac anomaly & Kabuki syndrome & Operation \\
\hline $\begin{array}{l}\text { Chen et al. (present } \\
\text { case) }\end{array}$ & 8 months old & No & No & No & Suspicious & No \\
\hline \multicolumn{7}{|l|}{ Bamman et al. (3) } \\
\hline Case 1 & 2.5 months old & $\begin{array}{l}\text { Respiratory and } \\
\text { inspiratory stridor }\end{array}$ & Distal tracheal stenosis & ASD & - & - \\
\hline Case 2 & - & - & Tracheal bronchus & - & - & - \\
\hline Case 3 & - & - & Distal tracheal stenosis & TOF, PDA & - & - \\
\hline Case 4 & - & - & Distal tracheal stenosis & TOF, PDA & - & - \\
\hline Case 5 & - & - & $\begin{array}{l}\text { Distal tracheal and } \\
\text { bilateral main-stem } \\
\text { bronchial stenosis }\end{array}$ & - & - & - \\
\hline Wang et al. (4) & & & & & & - \\
\hline Case 1 & 5 months old & Shortness of breath & & No & - & - \\
\hline Case 2 & 5 months old & - & & No & - & - \\
\hline Case 3 & 9 months old & - & & PDA & - & - \\
\hline Case 4 & 4 months old & Cough & & $\mathrm{COA}$ & Suspicion & - \\
\hline Case 5 & 38 months old & - & & DORV, VSD & - & - \\
\hline Case 6 & 2 months old & - & & VSD, ASD & - & - \\
\hline Case 7 & 40 months old & Cough & & PA/VSD & - & - \\
\hline Case 8 & 18 months old & - & & COA, PDA, VSD & - & - \\
\hline Case 9 & 27 months old & Shortness of breath & & TOF, PDA & - & - \\
\hline Mathias et al. (5) & 28 years old & - & $\begin{array}{l}\text { Tracheal bronchus, } \\
\text { Tracheal diverticulum }\end{array}$ & TOF & - & - \\
\hline \multicolumn{7}{|l|}{ Giudici et al. (6) } \\
\hline Case 1 & 3 years old & Cough & - & ASD & No & - \\
\hline Case 2 & 4 years old & - & - & VSD & Yes & - \\
\hline Case 3 & 7 years old & - & - & MS & Yes & - \\
\hline Collins et al. (7) & 4 years old & - & - & ASD & Yes & - \\
\hline Bhat et al. (8) & Newborn & - & - & $\mathrm{COA}$ & Yes & - \\
\hline Erickson et al. (9) & 2.5 years old & - & - & VSD & - & - \\
\hline Divekar et al. (10) & Newborn & - & - & TOF, TAPVC & - & - \\
\hline Ge et al. (11) & 2 months old & - & - & $\begin{array}{l}\text { DORV, ASD, VSD, LV } \\
\text { hypoplasia }\end{array}$ & - & - \\
\hline Collell et al. (12) & 5 years old & Stridor & - & - & - & - \\
\hline \multicolumn{7}{|l|}{$\begin{array}{l}\text { Fountain-Dommer et } \\
\text { al. (13) }\end{array}$} \\
\hline Case 1 & Newborn & - & - & $\begin{array}{c}\text { DORV, VSD, LV } \\
\text { hypoplasia, COA }\end{array}$ & - & Yes \\
\hline Case 2 & Newborn & - & - & $\mathrm{COA}$ & - & Yes \\
\hline Duong et al. (14) & 11 months old & - & - & VSD & - & Yes \\
\hline \multicolumn{7}{|l|}{ Sen et al. (15) } \\
\hline Case 1 & Newborn & - & - & $\begin{array}{l}\text { VSD, ASD, LV hypoplasia, } \\
\text { Aortic arch hypoplasia }\end{array}$ & - & No \\
\hline Case 2 & Newborn & - & - & $\begin{array}{l}\text { TOF, CHARGE } \\
\text { association }\end{array}$ & - & Yes \\
\hline
\end{tabular}

Because Kabuki syndrome is a very rare genetic disorder, its etiology remains unclear. Some studies have re- ported that it may be caused by a sporadic gene mutation, although not all cases of Kabuki syndrome have the same 
findings. PLPA could be a manifestation of cardiac defect in Kabuki syndrome. Although the patient in the current study had facial anomaly, a definitive diagnosis of Kabuki syndrome could not be made because there was no further genetic analysis and no other clinical features observed.

PLPA is basically left unaltered in all reported cases because the vascular anomaly itself does not result in a cyanotic condition or respiratory distress. Anatomical repair of the associated cardiac and respiratory system defects is a key factor in the patient's prognosis. Obstructed left heart lesions, such as hypoplastic left ventricle, coarctation of the aorta, and mitral valve hypoplasia, are indications for corrective surgery in patients with PLPA and seem to be more frequently accompanied by Kabuki syndrome (6).

In conclusion, PLPA is an exceedingly rare congenital vascular anomaly. It is likely a result of a developmental mistake of the LPA in the embryogenic phase, and it develops into an anomalous left lower lobe artery in most cases. This is the first case report of an anomalous left upper lobe artery. This condition could be associated with tracheobronchial anomaly or more often, with congenital cardiovascular defect or anomaly. Kabuki syndrome should be suspected in cases with multiple cardiovascular defects or anomalies. Echocardiography is the primary imaging technique for detecting vascular abnormalities and is used to determine the complete anatomy of the anomalous artery. The adjacent tracheobronchial abnormality can be detected on CT angiography, which is imperative if surgical correction is required.

\section{Footnotes}

Authors' Contributions: Drafting and critical revision of the manuscript was carried out by Chia-Hung Chen and Pei-San Tsai. Acquisition and analysis were performed by Kun-Shan Cheng and Yu-Peng Liu. Study concept, design, material support and supervision were done by Pei-San Tsai and Dao-Chen Lin. The final version of the manuscript was approved by all authors.

Conflict of Interests: All authors declare no conflict of interests.

Ethical Approval: The study has been approved by our Institutional Review Board.

Funding/Support: This manuscript is not funded or supported by any institute or company.

Informed Consent: Informed consent was obtained from all patients.

\section{References}

1. Jue KL, Raghib G, Amplatz K, Adams PJ, Edwards JE. Anomalous origin of the left pulmonary artery from the right pulmonary artery. Report of 2 cases and review of the literature. Am J Roentgenol Radium Ther Nucl Med. 1965;95(3):598-610. doi: 10.2214/ajr.95.3.598. [PubMed: 5321183].

2. Contro S, Miller RA, White H, Potts WJ. Bronchial obstruction due to pulmonary artery anomalies. I. Vascular sling. Circulation. 1958;17(3):418-23. doi: 10.1161/01.cir.17.3.418. [PubMed: 13511661].

3. Bamman JL, Ward BH, Woodrum DE. Aberrant left pulmonary artery. Clinical and embryologic factors. Chest. 1977;72(1):67-71. doi: 10.1378/chest.72.1.67. [PubMed: 872657].

4. Wang SY, Gao W, Zhong YM, Sun AM, Wang Q, Hu LW, et al. Multislice Computed Tomography Assessment of Tracheobronchial Patterns in Partial Anomalous Left Pulmonary Artery. J Comput Assist Tomogr. 2017;41(6):983-9. doi: 10.1097/RCT.0000000000000623. [PubMed: 28448421].

5. Mathias HC, Manghat NE. Partial anomalous left pulmonary artery with associated bronchial anomalies in a patient with repaired Tetralogy of Fallot. J Cardiovasc Comput Tomogr. 2012;6(4):292-4. doi: 10.1016/j.jcct.2012.04.011. [PubMed: 22732205].

6. Giudici V, Kanani M, Muthialu N, Carr M, Calder AD, Owens CM, et al. Duplicated left pulmonary artery: an unknown disease? Three case reports and review of the literature. Cardiol Young. 2016;26(2):340-6. doi: 10.1017/S1047951115000281. [PubMed: 25739970].

7. Collins R2, Weinberg PM, Goldmuntz E, Harris M. Images in cardiovascular medicine. Partial anomalous left pulmonary artery. Circulation. 2009;119(17):2405-7. doi: 10.1161/CIRCULATIONAHA.108.835942. [PubMed: 19414658].

8. Bhat AH, Davenport J, Cocalis M. Partial anomalous left pulmonary artery along with aortic coarctation in an infant with Kabuki syndrome. Echocardiography. 2012;29(6):E145-7. doi: 10.1111/j.15408175.2011.01651.x. [PubMed: 22324629].

9. Erickson LC, Cocalis MW, George L. Partial anomalous left pulmonary artery: new evidence on the development of the pulmonary artery sling. Pediatr Cardiol. 1996;17(5):319-21. doi: 10.1007/s002469900070. [PubMed: 8660448].

10. Divekar A, Coe JY, Saxena A. Tetralogy of Fallot, total anomalous pulmonary venous return, and partial anomalous left pulmonary artery: a rare association. Pediatr Cardiol. 2004;25(4):430-1. doi: 10.1007/s00246-003-9005-9. [PubMed:15085312].

11. Ge S, DeGroff CG, Knudson O, Strain J, Chan KC. Noninvasive assessment of pseudo-pulmonary artery sling by echocardiography and computerized tomography. Circulation. 2001;103(23):E115-6. doi: 10.1161/01.cir.103.23.e115. [PubMed: 11401948].

12. Collell R, Marimón C, Montero M. Partial Left Pulmonary Artery Sling. Revista Española de Cardiología (English Edition). 2010;63(7). doi: 10.1016/s1885-5857(10)70169-9.

13. Fountain-Dommer RR, Shirali GS, Wiles HB, Larsen RL. Noninvasive diagnosis of partial anomalous left pulmonary artery. J Am Soc Echocardiogr. 2001;14(7):745-6. doi: 10.1067/mje.2001.111878. [PubMed: 11447423].

14. Duong P, Mathur S, Miller OI. Partial anomalous left pulmonary artery. Eur Heart J Cardiovasc Imaging. 2018;19(2):237. doi: 10.1093/ehjci/jex242. [PubMed: 29040408].

15. Sen S, Winlaw DS, Sholler GF. Partial anomalous left pulmonary artery: report of two cases and review of literature. Cardiol Young. 2015;25(5):1012-4. doi: 10.1017/S1047951114001528. [PubMed: 25160653]. 